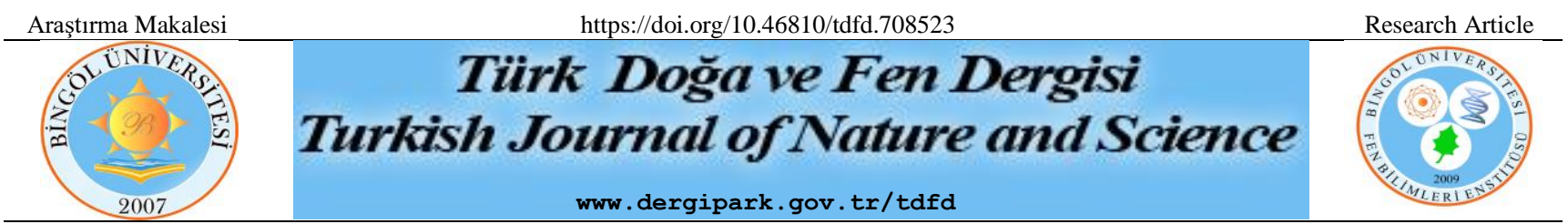

\title{
Doğu Akdeniz Bölgesinde Yetişen Dikenli incir (Opuntia Ficus-İndica L.) Tohumlarının Bazı Fiziksel Özelliklerinin Belirlenmesi Üzerine Bir Araştırma
}

\author{
Zeynep DUMANOĞLU ${ }^{1 *}$, Umral GUZEL $^{2}$, Atilla ÇAKIR $^{3}$ \\ ${ }^{1}$ Bingöl Üniversitesi, Ziraat Fakültesi, Biyosistem Mühendisliği Bölümü, Bingöl, Türkiye \\ ${ }^{2}$ Bozyazı Tarım ve Orman Müdürlüğü, Mersin, Türkiye \\ ${ }^{3}$ Bingöl Üniversitesi, Ziraat Fakültesi, Bahçe Bitkileri Bölümü, Bingöl, Türkiye \\ Zeynep DUMANOĞLU ORCID No: 0000-0002-7889-9015 \\ Umral GUZEL ORCID No: 0000-0002-7841-521X \\ Atilla ÇAKIR ORCID No: 0000-0001-9732-9272
}

*Sorumlu yazar: zdumanoglu@bingol.edu.tr

(Alınış: 25.03.2020, Kabul: 18.08.2020, Online Yayınlanma: 23.10.2020)

Anahtar
Kelimeler
Akdeniz,
Opuntia Ficus-
Indica,
Tohum
Boyutlar1,
Tohum
Özellikleri

Anahtar

Kelimeler

Opuntia Ficus-

Indica,

Tohum

Tohum

Özellikleri
Öz: Dikenli incir (Opuntia Ficus-İndica L.) Amerika ve Avrupa'da üretilen ve tüketilen bir meyve olmasına karşın ülkemizde Akdeniz ve Ege kıyı bölgelerdeki şehirlerde bilinmekte ve yetiştirilmektedir. Tüketiciler tarafından yerel pazarlara çıkış zamanları takip edilen bu meyvenin ticari boyutta üretilmesi ve işlenmesi için çalışmalar yapılmaktadır. Ayrıca ülkemizde yetişen bu meyvenin genetik konumu ve sslah çalışmaları da yapılmaktadır. Bu araştırma 2018-2019 yılları arasında yürütülmüştür. On dört farklı genotipten alınan tohumların bazı fiziksel özellikleri (şekil-boyut, yüzey alan, ortalama aritmetik-geometrik çap, küresellik, bin dane ağırlı̆ı̆) belirlenmiştir. Elde edilen sonuçlara göre; tohumların genel olarak 2,255-2,524 mm uzunluğa ve 1,666-2,044 mm genişliğe sahip olduğu saptanmıştır. Bu verilere göre, tohumların kısa ve oval bir yapıda; 4,097-6,250 g arasında bin dane ağırlı̆̆ıa sahip olduğu belirlenmiş̧tir.

\section{A Research on Determination of Some Physical Properties of İndian figs (Opuntia Ficus- Indica $\mathbf{L}$.) Seeds Grown in the Eastern Mediterranean Region}

Keywords

Mediterranean, Opuntia FicusIndica,

Seed Size,

Seed

Characteristic

\begin{abstract}
Although Opuntia Ficus-İndica L. is a fruit produced and consumed in America and Europe, it is grown only in cities in the coastal regions in our country. It is a fruit that is watched intensively by the consumers in the local markets. In this study, some physical properties of Opuntia Ficus-Indica plant seeds have been determined in order to increase the production possibilities of the this plant, to produce and process it commercially. In addition, the genetic location and breeding studies of this fruit grown in our country are also carried out. The study was carried out between 2018-2019. Opuntia Ficus-Indica seeds obtained from fruits with different fourteen genotypes collected from the Mediterranean region; some physical properties (shape-size, surface area, mean arithmeticgeometric diameter, sphericity, thousand grain weight) were determined. It was determined that Opuntia Ficus-Indica plant seeds generally have a length ranging from 2,255-2,524 $\mathrm{mm}$ and a width of $1,666-2,044 \mathrm{~mm}$. The seeds have a short and oval structure; it has been determined to have a weight of 4,097-6,250 g thousand grain.
\end{abstract}

\section{GíRíş}

Ülkemizde Akdeniz ve Ege Bölgelerinin özellikle kıyı şeridinde doğal olarak yetişebilme yeteneğine sahip olan familyasına ait bir bitkidir [1,2]. Yetiştiği bölgeye göre "hint inciri, papaz yemişi, frenk inciri ve babutsa" gibi farklı yerel isimlerle anılmaktadır [3]. Dikenli incir, Meksika orjinli olması ile birlikte genel olarak Akdeniz 
Bölgelerinde yaygın olan ve günümüzde pek çok ülkede kendiliğinden ya da kültüre alınarak yetiştirilmektedir [4, 5]. Kurak iklimlerin yanında daha çok subtropik iklim özelliklerine sahip olan bölgelerde yaygın olarak görülmektir [6]. Dikenli incir, dünyada tanınan bir ürün olmasına karşın, ülkemizde tüketicilerin yerel pazarları takip ederek ulaştıkları bir meyvedir. Ekonomik anlamda ülkemizde hak ettiği yere ulaşamayan bu meyve ile ilgili olarak ne yazık ki yapılan herhangi bir istatistiki bir çalışma da bulunmamaktadır.

Dikenli incire yol kenarlarında, tarım arazilerinin ya da konutların etraflarında rastlama olasılığı oldukça yüksektir [7]. Bu bitkinin sahip olduğu meyvelerin iriliği ile içerisinde yer alan tohumların miktarı doğrusal bir orantı ile artıp-azaldığı belirlenmiştir [8]. Ayrıca, dikenli bir yapıya sahip olduğundan, tüketiciye ulaştırma aşamasında meyve yüzeylerinde bulunan bu kısımlar yıkama-firçalama gibi işlemlerden geçirilerek temizlenmektedir [9].

Dikenli incir, gıda sektörünün yanında pek çok faydalarının bulunması sebebiyle sağlık sektörü tarafından da tercih edilmektedir. İçerdiği fenoller, flavaniodler, karotenler, linoleik asitler ile vitamin (C, E, $\mathrm{B}$ vitaminleri), mineraller ( $\mathrm{K}, \mathrm{Ca}, \mathrm{P}$ ve Se gibi) ve serbest aminoasitlerin (Alenin, Lisin, Fenilalenin gibi) [10, 11, 12], kardiovasküler rahatsızlıklar, diyabet ve kolesterol gibi günümüzde sık karşılaşılan sağlık problemlerine iyileştirici bir etkisi olduğu yapılan araştırmalar sonucunda belirlenmiştir $[13,14,15]$. İnsan sağlığını destekleyici ürünlerin içerisinde (yüksek miktarda mineral-ağırlıkça \%19,6, selüloz-ağırlıkça \%21,6 ve \%70 oranında polisakkaritler) bu bitkinin kullanımı da yaygınlaşmıştır [16].

Turuncu-Sarı gibi renklere sahip olan dikenli incir, genel olarak ülkemizde Ağustos-Eylül ayları arasında olgunlaşmakta ve sabah erken saatlerde hasadı yapılmaktadır. Kuzey Amerika gibi bölgelerde ise; daha çok kırmızı-mor gibi renklerde olabileceği gibi, yeşil hali de tüketiciler tarafından damak tadına bağlı olarak tercih edilebilmektedir [17]. Zoghlami ve ark.'nın (2002) yapmış olduğu araştırmaya göre; dikenli incir bitkisinin ekonomik verim yaşı 7-8 olarak tespit edilmiş ancak 2-3 yaşından itibaren de ürün alınabileceği fakat ticari olarak bu meyvelerin değerlendirilemeyeceği ortaya koymuştur [18].

Dünyadaki en önemli dikenli incir üretimi Meksika'da yapılmaktadır. Bu meyveyi yılda yaklaşık 812 t'luk bir üretim hacmiyle \%70'ni taze, \%30'unu işlenmiş gida olarak tüketicilere ulaştırdıkları belirtilmektedir [19, 20]. Ürünün, kabuk ve diken gibi kısımları meyvenin \%48'ini oluştururken, bu kısımlar ayrıldıktan sonra meyvenin içi tercihe bağlı olarak (taze, işlenmiş ürün) tüketilmektedir $[21,22,23]$. Dünyada farklı şekillerde ve sektörlerde yoğun olarak tüketilen bir meyve olması sebebiyle ürün işleme basamağı ayrıca önem taşımaktadır. Bitkinin hasadı, meyvelerinin ayrılması, dikenli kısımlarının meyve yüzeyinden temizlenesi ve akabinde hazırlanan ürünün üretim bandına alınması söz konusudur. Meyvenin kabuklarından, tohumlarından ve diğer aksamlarından ayrılarak iç kısmının çıkartılmasından sonra ise; ürün değerlendirileceği alana bağlı olarak (taze, işlenmiş gıda vb.) işletme içerisinde bir başka kısma alınmaktadır. İşlenmiş gıdaların içeriklerini vitamin ve mineral bakımından zenginleştirmek için bu tarz meyveler kullanmaktadır. Ayrica tıbbi alanda da kullanım söz konusudur. Bu nedenle, kullanım yerine bağlı olarak dikenli incir (meyve, kabuk, diken ve tohum vb.) değerlendirilmektedir.

Dikenli incir, ayrıca hayvan yemi, atık suların arıtılması $[24,25]$, erozyon kontrolü ve arazi sslahı gibi pek çok alanda da değerlendirilmektedir [26, 27, 28].

$\mathrm{Bu}$ çalışma, ülkemizde ekonomik olarak hedeflenen noktaya gelmesi için araştırmalara konu olan dikenli incir (Opuntia Ficus-İndica L.)'e ait 14 farklı genotipteki bitki materyali ile gerçekleştirilmiştir. Doğu Akdeniz Bölgesinden 7 farklı lokasyondan bu materyaller toplanmış; meyvelerinin içerisinde yer alan tohumlar elle temizlenerek araştırma için kullanılabilir forma getirilmiştir. $\mathrm{Bu}$ bitkiye ait tohumların bazı fiziksel özellikleri belirlenerek, genotipler arasındaki benzerfarklılıklar saptanmaya çalışılmıştır. Çalışmadan elde edilecek olan verilerin, ürün işleme basamağında, tercih edilecek ya da yeni tasarım-üretimi yapılacak olan aletmakine, ekipman ya da makine sistemlerinin doğru bir şekilde seçiminin yapılarak en az kayıp ile ürünün değerlendirilmesi için temel kaynak oluşturması ve ayrıca farklı genotiplerin incelenmesi sebebiyle ileride yapılacak olan genetik ve ıslah çalışmalarında bu verilerin araştırıcılara yardımcı olması amaçlanmıştır.

\section{MATERYAL VE METOT}

$\mathrm{Bu}$ çalışma, Doğu Akdeniz Bölgesinden (7 farklı lokasyon) 19.07.2018-16.08.2018 tarihleri arasında farklı dikenli incir (Opuntia Ficus-Índica L.) genotiplerinin meyvelerinden ayrılan tohumlar üzerinde yapılmıştır. Bu tohumlar, 2018-2019 yılları arasında Bingöl Üniversitesi Ziraat Fakültesi Bahçe Bitkileri ve Biyosistem Mühendisliği Anabilim Dalları ile Ege Üniversitesi Ziraat Fakültesi Tarım Makinaları ve Teknolojileri Mühendisliği Bölümüne ait laboratuvarlarda incelenmiştir.

On dört farklı dikenli incir (Opuntia Ficus-Índica L.) genotipi elle hasadı edilmiş meyvelerin içerisinden tohumlar yine aynı şekilde ayrılmıştır. Meyveden ayrılan ve temizlenen tohumlar rastgele olacak şekilde örneklenmiş ve bu tohumların bazı fiziksel özellikleri (şekil-boyut, yüzey alan, ortalama aritmetik-geometrik çap, küresellik, bin dane ağırlığ 1$)$ belirlenmeye çalışılmıştır. Çalışmada denemeler, üçer tekrarlı olacak şekilde tesadüf deneme parselleri deneme desenine göre gerçekleştirilmiştir. Elde edilen sonuçların analizi için SPSS V.21 istatistik programı kullanılarak $\mathrm{p}<0,05$ önemlilik düzeyinde, One-Way ANOVA ve DUNCAN gruplandırması istatistiki yöntemleri uygulanarak genotipler arasındaki değişim belirlenmeye çalışılmıştır. 


\subsection{Tohumların Fiziksel Özelliklerin Belirlenmesi}

\subsubsection{Tohumların Şekil-Boyut Özellikleri}

Şekil-boyut ölçüleri, genel olarak her tohuma özgü bir özelliktir. Tohumlar geometrik olarak uzun, orta veya kısa (Tablo 1) ve şekil özelliklerine bağlı olarak da yuvarlak, oval veya uzun (Tablo 2) olarak sinıflandırılmaktadır [29].

Tablo 1. Geometrik özelliklerine göre tohumların sınıflandırılması

\begin{tabular}{|c|c|}
\hline Tohum Geometrisi & $\begin{array}{c}\text { Tohum genişliği/Tohum uzunluğu } \\
(\mathbf{b} / \mathbf{a})(\mathbf{m m})\end{array}$ \\
\hline Uzun & 0,6 \\
\hline Orta & $0,6-0,7$ \\
\hline Kısa & $>0,7$ \\
\hline
\end{tabular}

Yapılan çalışmada, on dört farklı dikenli incir (Opuntia Ficus-Indica L.) bitkisinin genotiplerinden gelen tohumlar rastgele olacak şekilde örneklenmiş; her bir genotipten 100'er adet tohum Nexius Zoom marka bir stereo mikroskop (Mikroskop yazılımı: Image Focus V2.4) kullanılarak ölçülendirilmiştir [30].

Tablo 2. Tohum şekil özelliklerine göre tohumların sınıflandırılması

\begin{tabular}{|c|c|}
\hline Tohum Şekil Özellikleri & $\begin{array}{c}\text { Uzunluk (a), Genişlik (b), } \\
\text { Kalınlık (c) }(\mathbf{m m})\end{array}$ \\
\hline Yuvarlak & $\mathrm{a} \approx \mathrm{b} \approx \mathrm{c}$ \\
\hline Oval & $\mathrm{a} / 3<\mathrm{b} \approx \mathrm{c}$ \\
\hline Uzun & $\mathrm{c}<\mathrm{b}<\mathrm{a} / 3$ \\
\hline
\end{tabular}

\subsubsection{Yüzey alan}

İncelenen tohumların temel fiziksel özelliklerinden bir diğeri tohum yüzey alanlarının belirlenmesidir. Nexius Zoom marka stereo mikroskop kullanılarak (Image Focus 4.0 V2.4) her bir genotipten rastgele alınan 100'er adet tohumun yüzey alanları belirlenmiştir [31].

\subsubsection{Ortalama Geometrik Çap ve Ortalama Aritmetik Çap}

Ortalama aritmetik ve ortalama geometrik çap, yapılan çalışmalar sonrasında belirlenen eşitlikler kullanılarak on dört farklı genotipten elde edilen tohumlara ait değerler hesaplanmıştır. $\mathrm{Bu}$ hesaplamalarda kullanılan Eşitlik1 ve Eşitlik 2 [32, 33, 34] ile bu eşitliklerde kullanılan indisler aşağıda verilmiştir.

Ortalama Aritmetik Cap:

$$
\mathrm{D}:(\mathrm{L}+\mathrm{W}) / 2
$$

D: Tohuma ait aritmetik Çap (mm)

L: Tohuma ait uzunluk değeri $(\mathrm{mm})$

$\mathrm{W}$ : Tohuma ait genişlik değeri $(\mathrm{mm})$

Ortalama Geometrik Çap:

$$
\text { Do: }\left(L * D^{\wedge} 2\right)^{1} / 3
$$

$\mathrm{D}_{0}$ : Tohuma ait geometrik çap (mm)

L: Tohuma ait uzunluk değeri $(\mathrm{mm})$

D: Tohuma ait aritmetik çap (mm)

\subsubsection{Küresellik}

Tohumlara ait küresellik değeri uzunluk $(\mathrm{mm})$ değeri ve geometrik çap değeri kullanılarak hesaplanmaktadır. $\mathrm{Bu}$ değerin belirlemesinde, Eşitlik 3 kullanılmıştır [32, 33, 34].

Küresellik:

$$
\Phi: D o / L
$$

$\Phi$ : Tohumun küresellik değeri (birimsiz)

Do: Tohum ortalama geometrik çap (mm)

L: Tohum uzunluğu (mm)

\subsubsection{Bin Dane A ğırlığı}

Tohumların karakteristik özelliklerinden biri bin dane ağırlığıdır. Tohumun yapısına bağlı olarak değişkenlik gösteren bu değer, her tohum grubu için ayrı bir öneme sahiptir. Çalışmada, on dört farklı genotipten rastgele alınan tohumların bin dane ağırlıkları üçer tekrarlı olacak şekilde sayılmış ve 0,0001 g hassasiyetli Radwag AS 220.R2 analitik terazi kullanılarak tartılmıştır [35, 36].

\section{BULGULAR}

\section{1 Şekil-Boyut ve Yüzey Alan}

On dört farklı genotipten elde edilen tohumların incelenmesinin ardından, ortalama uzunluk bakımından en yüksek değeri 9. genotipten gelen tohumlarda $(2,524$ $\mathrm{mm}$ ) en düşük değeri ise 1. genotipten gelen tohumlarda $(2,255 \mathrm{~mm})$ belirlenmiştir. Benzer durum ortalama genişlik değerinde de kendisini göstermiş, en yüksek değeri 9. genotipten gelen tohumlar $(2,044 \mathrm{~mm})$, en düşük değeri ise 1. genotipten gelen tohumlar $(1,666$ $\mathrm{mm}$ ) ölçülmüştür. Yüzey alan değerlerinde de bu sıralama değişmemiş; en yüksek değeri 9. genotipten elde edilen tohumlarda $\left(4,312 \mathrm{~mm}^{2}\right)$ en düşük değer ise; 1. genotipe sahip olan tohumlarda $\left(3,113 \mathrm{~mm}^{2}\right)$ belirlenmiştir (Tablo 3).

Elde dilen verilere göre, bu tohumların şekil ve boyut özelikleri bakımında tüm genotiplerin k1sa tohum sınıfında yer aldığı ve şekil özellikleri bakımından ise oval taneler sınıfında yer aldığı belirlenmiştir. Yüzey alanı bakımından on dört farklı genotipten alınan dikenli incir tohumlarını incelendiğinde ise, uzunluk (mm) ve genişlik (mm) ölçülerinde olduğu gibi 1. genotipten alınan tohumların en düşük değeri aldığı ve diğer genotiplerden ayrıldığı belirlenmiştir. 9. genotipten gelen tohumların en yüksek yüzey alana sahip olduğu saptanmıştır (Tablo 3). 
Tablo 3. Dikenli İncir genotiplerine ait tohumların uzunluk, genişlik ve yüzey alan değerleri

\begin{tabular}{|c|c|c|c|c|c|c|}
\hline \multirow{2}{*}{$\begin{array}{c}\text { Genotip } \\
\text { No }\end{array}$} & \multicolumn{2}{|c|}{ Uzunluk (mm) } & \multicolumn{2}{|c|}{ Genişlik (mm) } & \multicolumn{2}{|c|}{$\begin{array}{c}\text { Yüzey } \\
\operatorname{alan}\left(\mathbf{m m}^{2}\right)\end{array}$} \\
\hline & Ort. & Stdv. & Ort. & Stdv. & Ort. & Stdv. \\
\hline 1 & $2,255^{\mathrm{a}}$ & 0,179 & $1,666^{\mathrm{a}}$ & 0,154 & $3, \mathbf{1 1 3}^{\mathrm{a}}$ & 0,315 \\
\hline 2 & $2,343^{b}$ & 0,710 & $1,811^{\mathrm{bc}}$ & 0,138 & $3,609^{\mathrm{cd}}$ & 0,315 \\
\hline 3 & $2,406^{\text {cde }}$ & 0,175 & $1,860^{\text {cdef }}$ & 0,190 & $3,705^{\text {def }}$ & 0,319 \\
\hline 4 & $2,395^{\mathrm{bcde}}$ & 0,178 & $1,813^{\mathrm{bc}}$ & 0,160 & $3,601^{\text {cd }}$ & 0,321 \\
\hline 5 & $2,389^{\text {bcde }}$ & 0,184 & $1,792^{\mathrm{b}}$ & 0,165 & $3,617^{\mathrm{c}}$ & 0,340 \\
\hline 6 & $2,415^{\mathrm{de}}$ & 0,171 & $1,915^{\mathrm{f}}$ & 0,172 & $3,828^{\mathrm{g}}$ & 0,302 \\
\hline 7 & $2,401^{\text {cde }}$ & 0,169 & $1,879^{\text {def }}$ & 0,211 & $3,703^{\mathrm{def}}$ & 0,411 \\
\hline 8 & $2,354^{\mathrm{bc}}$ & 0,155 & $1,826^{\text {bcde }}$ & 0,187 & $3,618^{\text {cd }}$ & 0,311 \\
\hline 9 & $2,524^{f}$ & 0,190 & $2,044^{\mathrm{g}}$ & 0,187 & $4,312^{h}$ & 0,453 \\
\hline 10 & $2,405^{\text {cde }}$ & 0,171 & $1,834^{\text {bcd }}$ & 0,140 & $3,645^{\text {cde }}$ & 0,291 \\
\hline 11 & $2,383^{\text {bcd }}$ & 0,140 & $1,890^{\mathrm{ef}}$ & 0,181 & $3,736^{\mathrm{efg}}$ & 0,285 \\
\hline 12 & $2,287^{\mathrm{a}}$ & 0,167 & $1,710^{\mathrm{a}}$ & 0,168 & $3,298^{\mathrm{b}}$ & 0,323 \\
\hline 13 & $2,439^{\mathrm{e}}$ & 0,165 & $1,862^{\text {cdef }}$ & 0,193 & $3,782^{\mathrm{fg}}$ & 0,377 \\
\hline 14 & $2,438^{\mathrm{de}}$ & 0,179 & $1,874^{\text {def }}$ & 0,177 & $3,187^{g}$ & 0,320 \\
\hline Ort. & 2,388 & 0,210 & 1,841 & 0,173 & 3,625 & 0,335 \\
\hline$p<0,05$ & \multicolumn{2}{|c|}{$\begin{array}{c}\text { Önem:0,00 } \\
\text { F:14,715 }\end{array}$} & \multicolumn{2}{|c|}{$\begin{array}{c}\text { Önem:0,00 } \\
\text { F:26,508 }\end{array}$} & \multicolumn{2}{|c|}{$\begin{array}{c}\text { Önem:0,00 } \\
\text { F:63,781 }\end{array}$} \\
\hline
\end{tabular}

Dikenli incir tohumlarının uzunluk $(\mathrm{mm})$ ve genişlik $(\mathrm{mm})$ verilerini istatistiki bakımdan $\mathrm{p}<0,05$ önemlilik düzeyinde incelediğimizde; One-Way ANOVA testi sonrasında genotipler arasında farklılıklar olduğu belirlenmiștir. Buna göre, değerlere DUNCAN gruplandırılması yapılmıştır. Tablo 3'te uzunluk değerleri bakımdan; 1. genotip ile 12. genotipten alınan tohumların; 3., 7. ile 10. genotiplerden alınan tohumları ve 4. ve 5. genotipten alınan tohumların kendi içlerinde benzer özelliklere sahip olduğu bu sebeple aynı grup içerisinde değerlendirilmiştir. En yüksek değeri alan 9.genotip ise diğer genotiplerden farklı olarak ayrı bir şekilde gruplandırılmıştır. Genişlik açısından ise; 1 . ve 12. genotip; 2 . ve 4 . genotipler ile 3 . ve 13 . genotiplerden gelen tohumlar kendi içlerinde benzer özellikler göstermiş ve aynı grup altında değerlendirilmiștir. Yüzey alan bakımındansa; 2. ve 4. genotip ile 3. ve 7. genotipler kendi içlerinde aynı grupta değerlendirilmiştir.

\subsection{Ortalama Aritmetik Çap ve Geometrik Çap ile Küresellik Değeri}

On dört faklı genotipten gelen tohumlar rastgele örneklenerek şekil-boyut özellikleri belirlendikten sonra ilgili eşitlikler kullanılarak tohumlara ait ortalama aritmetik çap $(\mathrm{mm})$, ortalama geometrik çap $(\mathrm{mm})$ ve küresellik (mm) değerleri hesaplanmıştır.

Tohumlar arasında en yüksek ortalama aritmetik çapın 9 . genotip tohumlarında $(2,284 \mathrm{~mm})$, en düşük değerin ise 1. genotipin tohumlarında $(1,961 \mathrm{~mm})$ olduğu belirlenmiştir. $\mathrm{Bu}$ durum, ortalama geometrik çap ve küresellik değerlerinde de saptanmıştır. En yüksek ortalama geometrik çap ve küresellik değerlerini 9 . genotipten gelen tohumlarda (sırasıyla $4,433 \mathrm{~mm}$ ve $1,745 \mathrm{~mm}$ ) en düşük değeri ise 1 . genotipten gelen tohumlarda (sirasiyla 2,916 $\mathrm{mm}$ ve $1,285 \mathrm{~mm}$ ) hesaplanmıştır (Tablo 4).
Tablo 4. Dikenli incir tohumlarının ortalama aritmetik ve geometrik çap değerleri ile küresellik değerleri

\begin{tabular}{|c|c|c|c|c|c|c|}
\hline \multirow[t]{2}{*}{$\begin{array}{c}\text { Genotip } \\
\text { No }\end{array}$} & \multicolumn{2}{|c|}{$\begin{array}{c}\text { Ortalama } \\
\text { Aritmetik Çap } \\
(\mathrm{mm})\end{array}$} & \multicolumn{2}{|c|}{$\begin{array}{c}\text { Ortalama } \\
\text { Geometrik Çap } \\
(\mathrm{mm})\end{array}$} & \multicolumn{2}{|c|}{$\begin{array}{c}\text { Küresellik } \\
\text { Değeri }\end{array}$} \\
\hline & Ort. & Stdv. & Ort. & Stdv. & Ort. & Stdv. \\
\hline 1 & $1,961^{\mathrm{a}}$ & 0,108 & $2,916^{a}$ & 0,502 & $1,285^{\mathrm{a}}$ & 0,141 \\
\hline 2 & $2,077^{\mathrm{c}}$ & 0,103 & $3,395^{\mathrm{b}}$ & 0,546 & $1,441^{\mathrm{c}}$ & 0,413 \\
\hline 3 & $2,133^{\text {efg }}$ & 0,124 & $3,680^{\text {def }}$ & 0,620 & $1,522^{\text {efg }}$ & 0,174 \\
\hline 4 & $2,104^{\text {cde }}$ & 0,119 & $3,565^{\text {bcde }}$ & 0,613 & $1,480^{\text {cde }}$ & 0,165 \\
\hline 5 & $2,091^{\mathrm{cd}}$ & 0,110 & $3,509^{\text {bcd }}$ & 0,586 & $1,461^{\mathrm{cd}}$ & 0,153 \\
\hline 6 & $2,165 \mathrm{~g}$ & 0,117 & $3,804^{f}$ & 0,627 & $1,567^{\mathrm{g}}$ & 0,171 \\
\hline 7 & $2,140^{\mathrm{fg}}$ & 0,135 & $3,702^{\text {ef }}$ & 0,666 & $1,533^{\mathrm{fg}}$ & 0,193 \\
\hline 8 & $2,095^{\mathrm{cd}}$ & 0,112 & $3,467^{\mathrm{bc}}$ & 0,532 & $1,467^{\mathrm{cd}}$ & 0,157 \\
\hline 9 & $2,284^{h}$ & 0,136 & $4, \mathbf{4 3 3}^{\mathrm{g}}$ & 0,801 & $1,745^{\mathrm{h}}$ & 0,207 \\
\hline 10 & $2,119^{\text {def }}$ & 0,101 & $3,628^{\text {cdef }}$ & 0,566 & $1,501^{\text {def }}$ & 0,143 \\
\hline 11 & $2,137^{\text {efg }}$ & 0,096 & $3,642^{\text {cdef }}$ & 0,470 & $1,525^{\mathrm{efg}}$ & 0,137 \\
\hline 12 & $1,999^{\mathrm{b}}$ & 0,110 & $3,071^{\mathrm{a}}$ & 0,503 & $1,336^{\mathrm{b}}$ & 0,145 \\
\hline 13 & $2,151^{\mathrm{fg}}$ & 0,109 & $3,784^{\mathrm{f}}$ & 0,572 & $1,546^{\mathrm{fg}}$ & 0,157 \\
\hline 14 & $2,156^{\mathrm{g}}$ & 0,113 & $3,808^{f}$ & 0,620 & $1,554^{\mathrm{g}}$ & 0,164 \\
\hline Ort. & 2,115 & 0,114 & 3,600 & 0,587 & 1,497 & 0,180 \\
\hline $\mathrm{p}<0,05$ & \multicolumn{2}{|c|}{$\begin{array}{c}\text { Önem:0,00 } \\
\text { F:44,343 }\end{array}$} & \multicolumn{2}{|c|}{$\begin{array}{c}\text { Önem:0,00 } \\
\text { F:36,106 }\end{array}$} & \multicolumn{2}{|c|}{$\begin{array}{c}\text { Önem:0,00 } \\
\text { F:44,303 }\end{array}$} \\
\hline
\end{tabular}

On dört farklı genotipten alınan dikenli incir bitkisine ait tohumların $\mathrm{p}<0,05$ önemlilik düzeyinde istatistiki olarak incelediğimizde; One-Way ANOVA testine göre genotipler arasında farklılıklar bulunduğu belirlenmiştir. Buna bağlı olarak veriler DUNCAN gruplandırması altında incelenmiştir. 1. genotipten alınan tohumların en düşük değeri aldığı, 9. genotipten alınan tohumların ise en yüksek değeri alarak her iki genotipinde diğer genotiplerden ayrıldığı değerlendirilmiştir. Diğer yandan; ortalama aritmetik çap bakımından genotipleri incelediğimizde, 3 . ve 11. genotip; 5. ve 8. genotip ile 7 . ve 13. genotipler kendi içlerinde benzer özellikler taşıdığından aynı şekilde gruplandırılmıştır. Ortalama geometrik çap açısından genotipleri incelediğimizde; 1.ve 12. genotip; 10 . ve 11 . genotip ile 6., 13. ve 14 . genotipler kendi içlerinde benzer özellikleri taşımları sebebiyle aynı grup içerisinde değerlendirilmiştir. Küresellik bakımdan ise; 3 . ve 11. genotipler; 5 . ve 8 . genotipler; 6 . ve 14 . genotipler ile 7 . ve 13 . genotipler kendi içlerinde aynı grup altında yer almıştır (Tablo 4).

\subsection{Bin Dane A Ăırlı̆ğ}

Dikenli incirin on dört farklı genotipinden elde edilen tohumların bin dane ağırlıkları belirlenirken, farklı hasat döneminde (19.07.2018-16.08.2018 tarihleri arasında) meyvelerden alınan tohumların bin dane ağırlıkları $(\mathrm{g})$ saptandıktan sonra her bir tohum grubu için belirlenen tohumların ortalaması bin dane ağırlıkları saptanmış [14] ve Tablo 5'da verilmiştir.

Diğer incelenen karakteristik değerlerden farklı olarak bu özellikte 1.ya da 9. genotiplerden farklı olarak 2. ve 11. genotiplerden alınan tohumlar ön plana çıkmış; 4. ve 12. genotipten alınan tohumlarda aynı değer $(5,103 \mathrm{~g})$ tartılmıştır. En yüksek ortalama bin dane ağırlığ 2.genotipte $(6,250 \mathrm{~g})$ belirlenirken, en düşük değeri 11 . genotipte yer alan tohumlarda $(4,097 \mathrm{~g})$ tartilarak belirlenmiştir (Tablo 5). 
Tablo 5. Dikenli İncir bitkilerine ait tohumların ortalama bin dane ağırlıkları

\begin{tabular}{|c|c|}
\hline Genotip No & $\begin{array}{c}\text { Ortalama Bin } \\
\text { dane } \\
\text { ağırlıkları (g) }\end{array}$ \\
\hline $\mathbf{1}$ & 5,517 \\
\hline $\mathbf{2}$ & 6,250 \\
\hline $\mathbf{3}$ & 5,777 \\
\hline $\mathbf{4}$ & 5,103 \\
\hline $\mathbf{5}$ & 4,603 \\
\hline $\mathbf{6}$ & 5,033 \\
\hline $\mathbf{7}$ & 4,647 \\
\hline $\mathbf{8}$ & 4,980 \\
\hline $\mathbf{9}$ & 6,090 \\
\hline $\mathbf{1 0}$ & 5,047 \\
\hline $\mathbf{1 1}$ & 4,097 \\
\hline $\mathbf{1 2}$ & 5,103 \\
\hline $\mathbf{1 3}$ & 5,170 \\
\hline $\mathbf{1 4}$ & 5,370 \\
\hline
\end{tabular}

Dikenli incir (Opuntia Ficus-Indica L.) Meksika meşeli olmasına karşın Avrupa ve Akdeniz ülkelerinin pek çoğunda üretilmekte ve tüketilmekte olan bir meyvedir. Lezzetli ve bir o kadar da vitamin-mineralce zengin meyveleri tüketiciler tarafindan tercih edilmektedir. Ancak ülkemizde daha çok Akdeniz ve Ege bölgelerindeki kentlerde yaşayanların aşina olduğu bu meyvenin ekonomik anlamda ticaretinin yapılabilmesi için kültüre alınarak, kontrollü şartlar altında yetiştirilmesine ihtiyaç duyulmaktadır. $\mathrm{Bu}$ nedenle, araştırıcılar tarafından çalışmalar sürdürülmektedir.

\section{SONUC}

Bu çalışmada, dikenli incir bitkisine (Opuntia FicusIndica L.) ait on dört farklı genotip ait Doğu Akdeniz Bölgesi bölgesinden, 7 farklı lokasyondan toplanmıştır. $\mathrm{Bu}$ meyvelerden alınan tohumların bazı fiziksel özellikleri belirlenmiştir. Bu fiziksel özelliklerden elde edilen veriler ayrıca $\mathrm{p}<0,05$ önemlilik düzeyinde istatistiki olarak da değerlendirilmiştir.

Dikenli incir tohumlarının genel olarak 2,255-2,524 mm arasında uzunluğa; 1,666-2,044 mm arasında genişliğe; tohumların kısa ve oval bir yapıya sahip olduğu belirlenmiştir. Farklı genotiplerden alınmasına karşın tohumların șekilsel ve yapısal olarak birbirine yakın değerler elde ettiği; bin dane ağırlıklarınınsa 4,097-6,250 $\mathrm{g}$ arasında olduğu saptanmıştır.

$\mathrm{Bu}$ araştırma sonucu ile elde edilen bu verilerin, hem taze hem de işlenmiş bir ürün olarak değerlendirilen dikenli incirin amaca uygun bir şekilde üretilmesi hedeflenmiştir. Ürün işleme aşamasında, farklı basamaklarda elde edilen bu veriler kullanılarak yeni alet-makine sistemlerinin efektif olarak değerlendirilebilecektir. Ayrıca, farklı genotiplere ait bu bilgilerin genetik açıdan araştırıcılara kaynak oluşturması ve yapılacak 1slah çalışmalarında değerlendirilmesi amaçlanmıştır.

\section{KAYNAKLAR}

[1] Yilmaz C. Dikenli incir (Opuntia ficus-indica L.) Agromedya Dergisi (5). 2013.

[2] Scheinvar L. FAO Plant Production and Protection. Eds: Barbera G., Inglese P. Pimienta BE. FAO, Food and Agriculture Organization of the United Nations, 1995; p:20-27.

[3] Güzel U. Mersin ve Çevresinde Yetişmekte Olan Bazı Dikenli İncirlerde (Opuntia ficus-indica L.) En Uygun Hasat Dönemlerinin Saptanması, Bingöl Üniv. Ziraat Fak. Bahçe Bitkileri ABD., Yüksek lisans tezi; 2019.

[4] Inglese P, Basile F, Schirra M. Cacti:Biologyand uses,California-USA, University of California Press. 2002;p:163-183.

[5] Mashope BK. Characterization of cactus pear germplasm in South Africa. Thesis, Department of Plant Sciences, University of the Free State, Bloemfontein, South Africa, Ph.D. 2007.

[6] Yılmaz C. Dikenli incir (Opuntia ficus-indica L.) yetiştiriciliği, Tarım Türk (24) 2010, 1416.

[7] Ak BE. Cactus pear (opuntıa ficus-indica mill.) in Turkey: growing regions and pomological traits of cactus pear fruits. Acta Hort. (ISHS); 728,2006;p:51 - 54 .

[8] Karababa E, Coskuner Y, Aksay S. Some Physical Fruit Properties Of cactus pear (Opuntia spp.) that grow wild in the eastern mediterranean region of Turkey. J-PACD; 2004.

[9] Dimitris L, Pompodakis N, Markellou E, Lionakis SM. Storage response of cactus pear fruit following hot water brushing. Postharvest Biol Tec.,38(2): 2005; p:145-51.

[10] El-Razek FHA., Hassan AA. Nutritional value and hypoglycemic effect of prickly cactus pear (Opuntia ficus-indica) fruit juice in alloxan-induced diabetic rats, Australian Journal of Basic and Applied Sciences, 5 (10): 2011;p:356-377.

[11] Ghazi Z, Ramdani M, Tahri M, Rmili R, Elmsellem H. Chemical composition and antioxidant activity of seeds oils and fruit juice of Opuntia ficus indica and Opuntia dillenii from Morocco, Journal of Materials and Environmental Science, 6 (8): 2015; p:2338-2345.

[12] Wan J, Chakraborty T, Xu CC, Madhumita BR. Treatment train for tailings pond water using Opuntia ficus-indica as coagulant, Separation and Purification Technology 211; 2019; p:448-455.

[13] Frati A. Medical implication of prickly pear cactus 3rd Annual Texas prickly pear council. Kingsvile:1992; p:29-34.

[14] Gurbachan S, Felker P. Cactus: new world foods. Indian Hort, 43(1); 1988; p:29-31. 
[15] Stintzing FC., Schieber A, Carle R. Phytochemical and nutritional significance of cactus pear. Eur Food Res Technol 212; 2001; p:396-407.

[16] Scaffaro R, Maio A, Gulino EF, Megna B. Structure-property relationship of PLA-Opuntia Ficus Indica biocomposites. Composites Part B 167;2019; p:199-206.

[17] Barbera G, Carimi F, Inglese P, Panno M. Physical, morphological and chemical changes during fruit development and ripening in three cultivars of prickly pear, Opuntia ficus-indica (L.) Miller. J Hortic Sci 67(3): 1992; p:307-12.

[18] Zoghlami N, Chrita I, Bouamama B, Gargouri M, Paolo I, Filadelfio B, Mario S, et al. Cacti: Biology and Uses. Ed: Nobel, P.S., University of California Press, Ltd.; 2002.

[19] SIAP, Servicio de Informacion Agroalimentaria y Pesquera Retrieved (https://www.gob.mx/siap); 2018.

[20] López-Domínguez CM, Ramírez-Sucre MO, Rodríguez-Buenfil IM. Enzymatic hydrolysis of Opuntia ficus-indica cladode by Acinetobacter pittii and alcohol fermentation by Kluyveromyces marxianus: $\mathrm{pH}$, temperature and microorganism effect, Biotechnology Reports 24; 2019; e0 0384.

[21] Aksay S, Coşkuner Y, Karababa E, Ekiz İH. Physical, chemical and tecnological properties of prickly pear (opuntia spp.) fruits. Gida Mühendisliği Kongre ve Sergisi: 1998; p:281-9.

[22] Coşkuner Y, Türker N, Ekiz HI, Aksay S, Karababa E. Effect of $\mathrm{pH}$ and temperature on the thermostability of prickly pear (Opuntia ficusindica) yelloworange pigments, Nahrung 44(4): 2000; p:261-263.

[23] Türker N, Coşkuner Y, Ekiz Hİ, Aksay S, Karababa E. The Effect of Fermentation on the Thermostability of Yellow-Orange Pigments Extracted from Cactus Pear (Opuntia ficus-indica). European Food Research and Technology, 212; 2011; p:213-216.

[24] Young KA. The mucilage of Opuntia Ficu- Indica: A natural, sustainable, and viable water treatment technology for use in rural Mexico for reducing turbidity and arsenic contamination in drinking water, J. Electrochem. Soc. 129; 2006; 178.

[25] Pichler T, Young K, Alcantar N. Eliminating turbidity in drinking water using the mucilage of a common cactus, Water Sci. Technol. Water Supply $12 ; 2012 ; 179$.

[26] Le Houérou HN. The role of cacti (Opuntia spp.) in erosion control, lan reclamation, rehabilitation and agricultural development in the Mediterranean Basin. J. Arid Environ. 33 (2); 1996; p:135-159.

[27] Paiva PMG, de Souza IFAC, Costa MCVV, Santos ADFS, Coelho LCBB. Opuntia sp. cactus: biological characteristics, cultivation and applications. Adv. Res. 7 (3); 2016; p: 1-14.

[28] Krümpel J, George T, Gasston B, Francis G, Lemmer A. Suitability of Opuntia ficus-indica (L) Mill. and Euphorbia tirucalli L. as energy crops for anaerobic digestion, Journal of Arid Environments 174; 2020;104047.

[29] Yağcığlu A. Ürün İşleme, Ege Üniv. Yayınları Ziraat Fakültesi Yayın No: 517, Genişletilmiş 2. Baskı; 2015.

[30] Dumanoğlu Z, Ozkan SS, Topcu GD. İtalyan çimi (Lolium multiflorum L.) çeşitlerine ait tohumların bazı fiziksel özelliklerinin belirlenmesi, Uluslararası Tarım ve Yaban Hayatı Bilimleri Dergisi (UTYHBD); 5(2): 2019; p:292 - 298.

[31] Dumanoğlu Z, Çakmak B. Tohum Uygulamalarının Soğan (Allium cepa

L.) Tohumunun Bazı Fiziksel ve Mekanik Özelliklerine Etkisi, Bursa Uludağ Üniv. Ziraat Fak. Dergisi, 33(1) 2019, p:53-66;

[32] Mohsenin NN. Physical Properties of Plant and Animal Materials. Gordon and Breach Science Publishers; 1970.

[33] [33] Alayunt FN. Biyolojik Malzeme Bilgisi, Ege Üniv. Ziraat Fakültesi Tarım Makineleri Bölümü Ders Kitabı, Ege Üniv. Ziraat Fak. Yayınları No: 541; 2000.

[34] Kara M. Biyolojik Ürünlerin Fiziksel Özellikleri, Atatürk Üniv. Ziraat Fakültesi Yayınları No: 242; 2012.

[35] International Rules for Seed Testing (ISTA). International Rules for Seed Testing Book; 2007.

[36] Dumanoğlu Z, Dönmez C, Çakır MF. General Characteristics of Seeds of Some Anise (Pimpinella anisum L.) Lines and Effects of Film Coating on These Seeds, Turkish Journal of Agriculture - Food Science and Technology (TURJAF); 8(1): 2020; p:46-53. 